\title{
ANATOMICAL VARIATIONS IN ORIGIN OF THE INFERIOR PHRENIC ARTERY- A CROSS SECTIONAL STUDY
}

\author{
M. Shefna ${ }^{1}$, Lola Das ${ }^{2}$, Girijamony V. $K^{3}$
}

${ }_{1}^{1}$ Assistant Professor, Department of Anatomy, Travancore Medical College, Thazhuthala, Kerala, India.

2Professor and HOD, Department of Anatomy, Government Medical College, Manjery, Kerala, India.

${ }^{3}$ Former Professor and HOD, Department of Anatomy, Government Medical College, Thrissur, Kerala, India.

\section{ABSTRACT}

\section{BACKGROUND}

The inferior phrenic arteries are a pair of important vessels, supplying multiple organs including the diaphragm, adrenal glands, oesophagus, stomach, liver, inferior vena cava, and the retro peritoneum. Knowledge of the vessel of origin of inferior phrenic artery is clinically important because, this artery is the most common extrahepatic source of blood supply to hepatocellular carcinomas in the bare area of liver and it is embolized as a treatment for the same. An aberrant inferior phrenic artery can also be a source of haemoptysis or an unidentified intra-abdominal bleed following trauma or surgery. We wanted to identify the variations in origins of right and left inferior phrenic arteries.

\section{METHODS}

The study was conducted on 60 adult post-mortem specimen and 20 formalin fixed adult cadavers to identify the origin of right and left inferior phrenic arteries.

\section{RESULTS}

The typical aortic origin of right inferior phrenic artery was found in 43 cases $(53.75 \%)$ while that of left inferior phrenic artery was found in 54 cases (67.5\%). The celiac trunk gave off inferior phrenic artery in 52 cases. In 4 cases, they originated as branches of renal artery, more on the right side. A common trunk that divides into right and left inferior phrenic arteries was found in 2 cases. The vessel of origin was found to be hepatic artery in 2 cases. In a unique case, the right inferior phrenic artery was arising together with other lateral branches of abdominal aorta as a common trunk.

\section{CONCLUSIONS}

Variation in the origin of inferior phrenic artery (Non-aortic origin) is $39.38 \%$, more on the right. There is no significant sex difference. The embryological basis for variations is discussed and a review of available literature is made.

\section{KEY WORDS}

Inferior Phrenic, Abdominal Aorta, Variations, Hepatocellular Carcinoma, Blood Supply, Diaphragm, Abdominal Surgery, Cadaveric Study, Embryological Basis

HOW TO CITE THIS ARTICLE: Shefna M, Das L, Girijamony VK. Anatomical variations in origin of the inferior phrenic artery- a cross sectional study. J. Evolution Med. Dent. Sci. 2019;8(24):1957-1961, DOI: 10.14260/jemds/2019/430

\section{BACKGROUND}

Inferior phrenic arteries are important blood vessels that supply the under surface of diaphragm, the supra renal glands, the bare area of liver and the retro peritoneum. It also supplies inferior vena cava, oesophagus and parts of stomach ${ }^{1}$. According to typical textbook description, right and left inferior phrenic arteries are the first lateral branches of abdominal aorta, given off at the level of celiac trunk, as soon as the aorta enters the abdomen ${ }^{2}$. A lot of variations are seen in the origin of these vessels. The knowledge of variations is important to identify the origin of inferior phrenic artery during embolization of feeding vessels of a hepatocellular carcinoma ${ }^{3,4}$ or when the inferior phrenic artery bleeds into

'Financial or Other Competing Interest': None.

Submission 30-04-2019, Peer Review 01-06-2019,

Acceptance 07-06-2019, Published 17-06-2019.

Corresponding Author:

Dr. M. Shefna,

Assistant Professor

Department of Anatomy,

Travancore Medical College,

Thattamala, Kollam-691020, Kerala, India.

E-mail:dr.shefnajassar@gmail.com

DOI: $10.14260 /$ jemds $/ 2019 / 430$ the peritoneum following trauma or when an unusual inferior phrenic artery is the cause of a haemoptysis5,6. Also, bleeding due to problems like Mallory Weiss syndrome or gastro oesophageal cancer may be related to inferior phrenic artery.

\section{METHODS}

The study was done on 20 cadavers dissected at the Department of Anatomy and 60 autopsy specimens obtained from the Department of Forensic Medicine, Government Medical College, Thrissur.

Of the 80 adult human cadavers studied, 14 had multiple renal arteries. The association between presence of variations in inferior phrenic artery and presence of multiple renal arteries was found to be statistically insignificant ( $p$ value by chi-square test $=0.17$ ).

\section{Inclusion Criteria}

1. Cadavers used for routine dissection during the study period in the Department of Anatomy.

2. Autopsy cases, with intact abdominal wall and age above 18 years, done in Department of Forensic Medicine. 


\begin{tabular}{|c|c|c|c|}
\hline \multirow{2}{*}{$\begin{array}{c}\text { Right Inferior Phrenic } \\
\text { Artery }\end{array}$} & \multicolumn{2}{|c|}{ Gender } & \multirow[t]{2}{*}{ Total } \\
\hline & Male & Female & \\
\hline From aorta & $34(54.0 \%)$ & $9(52.9 \%)$ & $43(53.8 \%)$ \\
\hline From celiac trunk & $24(38.1 \%)$ & $5(29.4 \%)$ & $29(36.2 \%)$ \\
\hline From renal artery & $2(3.2 \%)$ & $1(5.9 \%)$ & $3(3.8 \%)$ \\
\hline From hepatic artery & $1(1.6 \%)$ & $1(5.9 \%)$ & $2(2.5 \%)$ \\
\hline $\begin{array}{l}\text { As a common trunk with } \\
\text { other lateral branches }\end{array}$ & $1(1.6 \%)$ & $0(0.0 \%)$ & $1(1.2 \%)$ \\
\hline $\begin{array}{l}\text { Right and left arise as a } \\
\text { common trunk }\end{array}$ & $1(1.6 \%)$ & $1(5.9 \%)$ & $2(2.5 \%)$ \\
\hline Total & $63(100.0 \%)$ & $17(100.0 \%)$ & $80(100.0 \%)$ \\
\hline \multicolumn{4}{|c|}{ Table 1. Variable Origins of Right Inferior Phrenic Artery } \\
\hline
\end{tabular}

\begin{tabular}{|c|c|c|c|}
\hline \multirow{2}{*}{$\begin{array}{c}\text { Origin of Left Inferior } \\
\text { Phrenic Artery }\end{array}$} & Male & Female & \multirow{2}{*}{ Total } \\
\cline { 2 - 4 } & $44(69.8 \%)$ & $10(58.8 \%)$ & $54(67.5 \%)$ \\
\hline From aorta & $24(38.1 \%)$ & $6(35.3 \%)$ & $23(28.8 \%)$ \\
\hline From celiac trunk & $1(1.6 \%)$ & $0(0.0 \%)$ & $1(1.2 \%)$ \\
\hline From renal artery & $1(1.6 \%)$ & $1(5.9 \%)$ & $2(2.5 \%)$ \\
\hline $\begin{array}{c}\text { Right and left arise as } \\
\text { common trunk }\end{array}$ & $\mathbf{6 3 ( 1 0 0 . 0 \% )}$ & $\mathbf{1 7}(100.0 \%)$ & $\mathbf{8 0}(100.0 \%)$ \\
\hline Total & \multicolumn{3}{|c|}{ Table 2. Variable Origins of Left Inferior Phrenic Artery } \\
\hline \multicolumn{4}{|r}{}
\end{tabular}

\begin{tabular}{|c|c|c|c|c|c|}
\hline & Class A & Class B & Class C & Class D & Class E \\
\hline Pulakunta et al $^{7}$ & $6.25 \%$ & $87.5 \%$ & $3.13 \%$ & $3.13 \%$ & \\
\hline Kahn et al ${ }^{8}$ & $52 \%$ & $46 \%$ & $9 \%$ & & \\
\hline Piao et al $^{9}$ & $28.2 \%$ & $61.6 \%$ & $4.3 \%$ & $2.9 \%$ & \\
\hline Gokan et al ${ }^{4}$ & $46.2 \%$ & $38.5 \%$ & $15.4 \%$ & & \\
\hline Basile et $\mathrm{al}^{10}$ & $41 \%$ & $49 \%$ & $5.5 \%$ & & $0.5 \%$ \\
\hline $\begin{array}{c}\text { Akhilandeswari } \\
\text { et al }{ }^{11}\end{array}$ & $28 \%$ & $53 \%$ & $16 \%$ & & \\
\hline Loukas et $\mathrm{al}^{6}$ & $\begin{array}{c}\text { Right : } \\
40 \% \\
\text { Left : } 47 \%\end{array}$ & $\begin{array}{c}\text { Right: } \\
38 \% \\
\text { Left: } 45 \%\end{array}$ & $\begin{array}{c}\text { Right: } \\
17 \% \\
\text { Left: } 5 \%\end{array}$ & $\begin{array}{c}\text { Right: } \\
3 \% \\
\text { Left: } 2 \%\end{array}$ & $\begin{array}{c}\text { Right: } \\
2 \% \\
\text { Left : } 1 \%\end{array}$ \\
\hline Present study & \begin{tabular}{|c|} 
Right: \\
$36 \%$ \\
Left: $29 \%$
\end{tabular} & $\begin{array}{c}\text { Right: } \\
54 \% \\
\text { Left : } 68 \%\end{array}$ & $\begin{array}{c}\text { Right: } \\
3.8 \% \\
\text { Left : } 1.2 \%\end{array}$ & 0 & $\begin{array}{c}\text { Right: } \\
3 \% \\
\text { Left : } 0\end{array}$ \\
\hline
\end{tabular}

Table 3. Classes of Inferior Phrenic Arteries Obtained in Various Studies

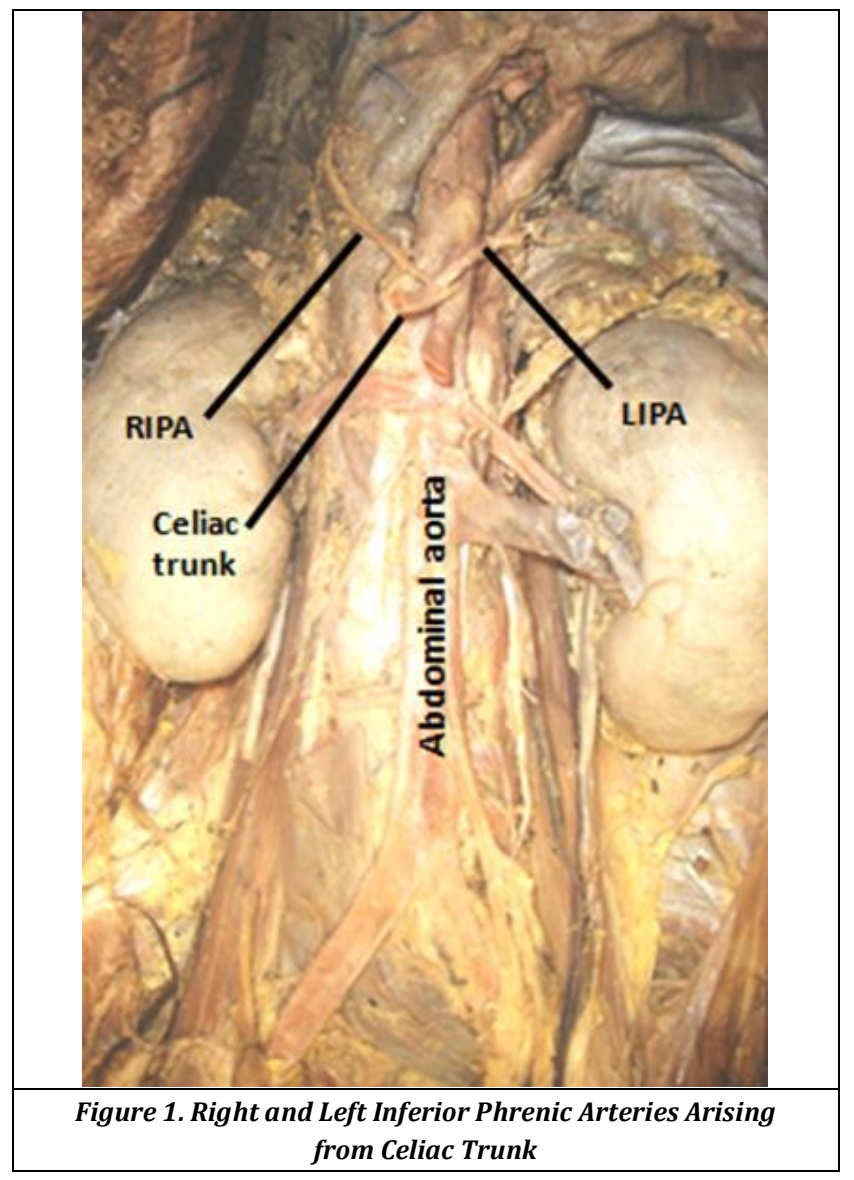

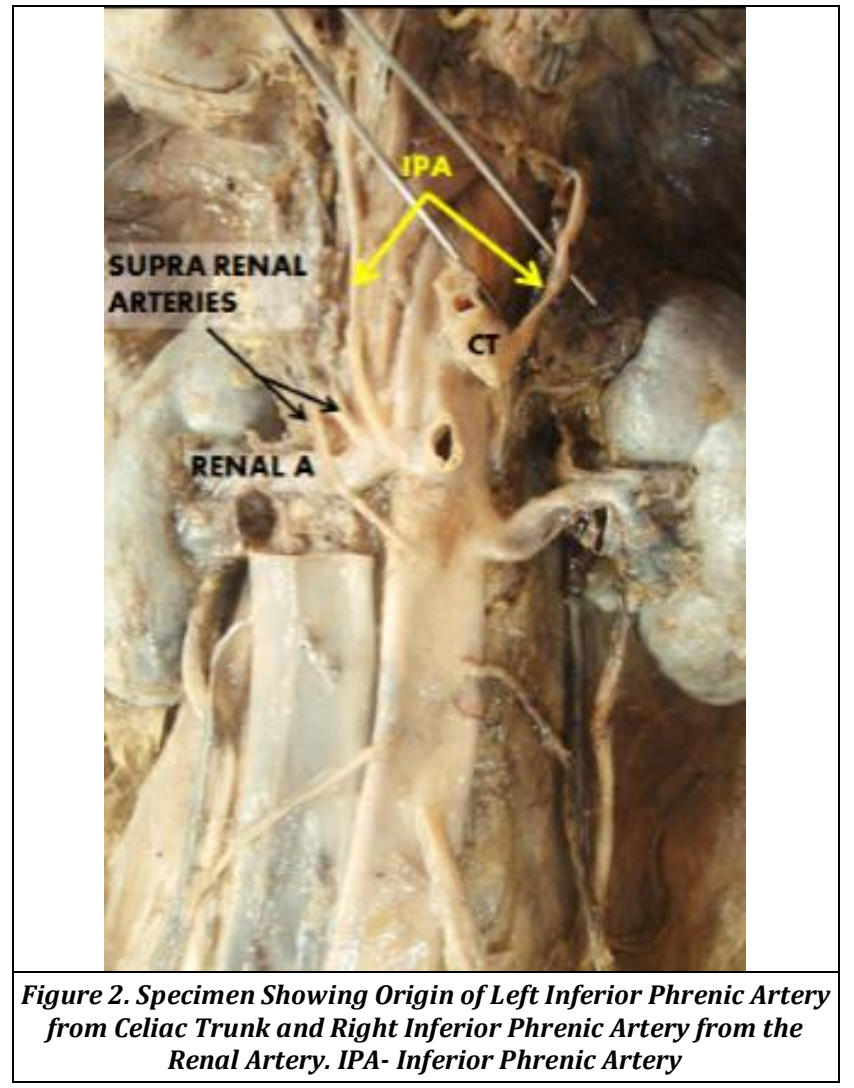

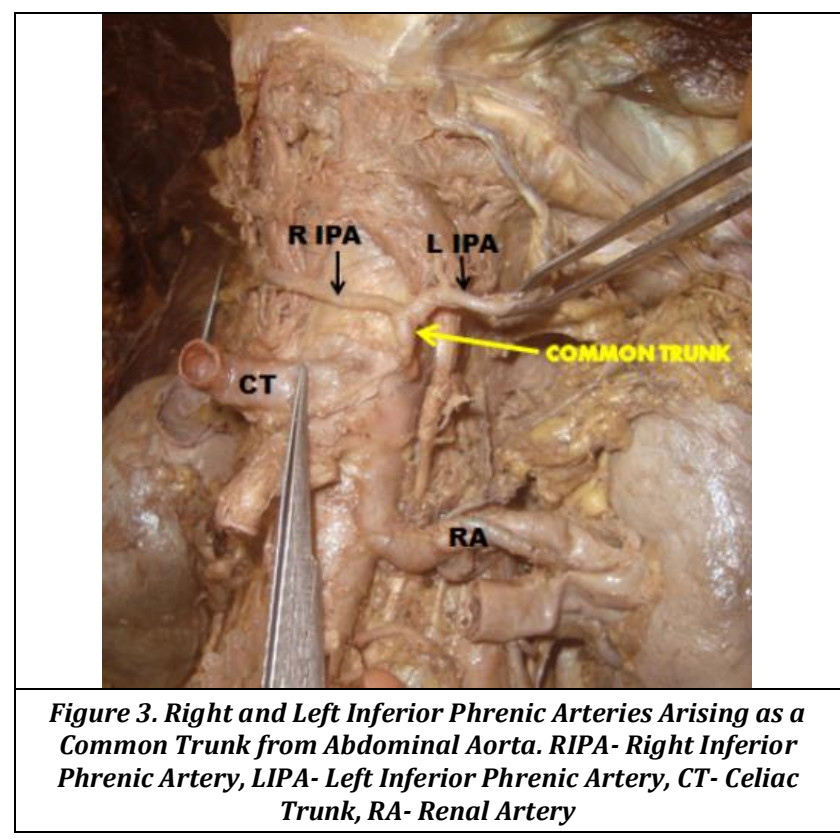

\section{Exclusion Criteria}

- Cases which had underwent abdominal surgeries.

- Tumours or mass in the abdomen.

- Cases of abdominal trauma.

- Cases of death by burns.

- Decomposed bodies.

\section{In the Cadavers}

After opening the abdominal cavity, abdominal aorta and its branches were explored by mobilizing abdominal organs. Inferior phrenic arteries were identified on the under surface of diaphragm and were traced to their origins (Figure 1). The number of renal arteries on each side was also noted. 


\section{In the Autopsy Specimen}

On the visceral specimen taken out during autopsy, abdominal aorta was opened longitudinally from the posterior aspect to look for the openings of right and left inferior phrenic arteries from aorta. If any one or both openings are not seen, the corresponding inferior phrenic artery was traced from the under surface of diaphragm towards its origin and the artery of origin of each inferior phrenic artery was noted (figure 2). Sex of the deceased was also noted.

The number of renal arteries on each side was also noted.

\section{Statistical Analysis}

The collected data was entered in Microsoft Excel worksheet and analysed using SPSS version 16 software. Demographic data was analysed using frequency and percentage. Chi square test and Fischer's exact test were used to find the statistical significance.

\section{RESULTS}

Of the 160 inferior phrenic arteries studied, an atypical origin was found in 63 (39.38\%).Non aortic origins are found to be more on the right side. Various vessels of origin of inferior phrenic arteries as well as a comparison of variable origins in both sexes is made in table 1 and table 2 . Analysis of these results showed that difference between sexes in relation to origin of these arteries was not significant statistically ( $p$ value calculated by Fishers exact test $=0.4$ ).

\section{DISCUSSION}

The Grays Anatomy explains the origins of inferior phrenic arteries from both celiac trunk and aorta, as well as describes the common trunk origins. It also mentions alternative origins including renal, accessory renal, left gastric, hepatic and gonadal arteries. Inferior phrenic artery, if a branch of aorta, originated as the first lateral branch, arising at the level of aortic orifice of the diaphragm (T12). In the present study, of the 160 inferior phrenic arteries studied, an aortic origin was seen in $60.6 \%$ cases. The second most common origin of inferior phrenic artery was found to be from the celiac trunk (32.5\%). A lot of studies have been done on inferior phrenic artery because it is found to be the most common extra hepatic blood supply of carcinomas in the bare area of liver as observed by various researchers like Gwon et al, Loukas et aland Yahel et al.12,6,13

The variations in origin of inferior phrenic artery range from $38 \%$ to $62 \%$ in various study populations. This should be kept in mind during any interventional procedures done in upper abdomen.

\section{Arteries into Five Classes- \\ 1. Class A-from celiac trunk. \\ 2. Class B- from abdominal aorta. \\ 3. Class C- from renal artery. \\ 4. Class D- from right gastric artery. \\ 5. Class E- from hepatic artery.}

Loukas et al $^{6}$ Categorized the Origin of Inferior Phrenic

Using this classification, results obtained by various researchers are compared in table 3 . From this, it can be observed that Kahn et al, Gokan et al and Loukas et al found Celiac trunk to be the most common vessel of origin while in studies done by Pulakunta et al, Piao et al, Basile et al, Akhilandeswari et al and in our study, abdominal aorta is the most common vessel of origin of the inferior phrenic artery. We did not find any inferior phrenic artery coming under class D (gastric artery).

Of the three studies done on South Indian population, the present study and study done by Akhilandeswari et al shows origin of inferior phrenic arteries from aorta slightly more in frequency than their origin from celiac trunk, while study by Pulakunta et al showed a wide difference in frequencies of origin from aorta and celiac trunk. Renal artery was the third common artery of origin for inferior phrenic arteries in all study populations. Gastric and hepatic origins were rarely observed.

Apart from the vessels of origins listed above, Piao et al (1998) found that these arteries are also arising from middle suprarenal artery in $2.9 \%$ cases (4 out of 138 arteries studied), Akhiladeswari et al found that of the 32 cadavers studied, inferior phrenic artery was arising from superior mesenteric artery in a single case and in our study, we found a common trunk from right side of aorta giving off inferior phrenic artery along with two supra renal arteries and gonadal artery, for which we could not find any previous records. These are the three rarest origins described so far.

\section{Embryological Basis}

A possible explanation for the presence of these variable origins and common trunks of inferior phrenic artery can be made by reviewing the development of the dorsal aorta and its branches.

Dorsal aorta gives three sets of branches-

1. Ventral splanchnic branches to the gut and its derivatives.

2. Lateral splanchnic branches to the intermediate mesoderm and its derivatives.

3. Somatic intersegmental branches to the body wall and the neural tube.

Of these, the lateral splanchnic branches are the group that is relevant here. They supply the pronephros, mesonephros and metanephros. Most of the lateral branches undergo regression in the later part of development. The gonadal artery and three suprarenal arteries persist on each side. The inferior phrenic artery buds out from the upper suprarenal artery and the renal artery buds out from the lower suprarenal artery. Inferior phrenic and renal arteries establish communication with abdominal aorta. Later on, the upper and lower suprarenal arteries loss their connection with aorta and hence appear as branches of the inferior phrenic and the renal arteries respectively in the fully formed human being. ${ }^{14}$ When the branches to pronephros and mesonephros arise together, a common trunk as we got in the rare case can result. This also explains the origin of inferior phrenic artery from other lateral branches like suprarenal artery, renal artery or gonadal artery. Any aberrant connection between the lateral and ventral branches of dorsal aorta can cause some other variations discussed above. This explains origin of inferior phrenic artery from ventral branches like celiac trunk or its branches like hepatic artery and gastric artery. 
Duprat et al analysed the role of inferior phrenic artery embolization in the treatment of hepatocellular carcinomas. The right inferior phrenic arteries were found to supply a major proportion of hepatocellular carcinomas. They conducted 29 inferior phrenic artery embolizations. Except for one case of pleural effusion, there were no major complications. So, the study concludes that, embolization of inferior phrenic arteries is a safe and effective treatment modality for treating hepatocellular carcinomas of bare area of liver. Hence, they stress on the importance of knowing the origin of inferior phrenic artery. ${ }^{15}$

Gokan et al studied the extra-hepatic collateral blood supply of hepatocellular carcinomas using helical CT scans in 121 patients with hepatocellular carcinoma. Among them 16 patients had hepatocellular carcinoma supplied by the right inferior phrenic artery. This was evident from the increased diameter of the right inferior phrenic artery when compared to the left. During their study, they traced the origins of right inferior phrenic artery. ${ }^{4}$

In the study done by Gwon et al, 383 interventional procedures related to the inferior phrenic arteries were done. They found that inferior phrenic arteries of both sides arose from the aorta and the celiac trunk with equal frequencies and from the renal artery with a lesser frequency. They were also found to arise from various other sites like left gastric artery, hepatic artery, superior mesenteric artery, spermatic artery and adrenal arteries. ${ }^{7}$

In their radiological study, Basile et al observed the variations in origin of right inferior phrenic artery in view of being potential supply to hepatocellular carcinomas. They found that the inferior phrenic arteries of both sides arose in 13 different types of combinations among them. ${ }^{10}$

All these point to the fact that need for knowledge of origin and course of inferior phrenic arteries is increasing. Studies done in this regard would help to perform chemoembolization of feeding vessels of hepatocellular carcinoma more precisely.

\section{CONCLUSIONS}

We found wide variations in the origin of inferior phrenic arteries, with abdominal aorta being the most common vessel of origin $(60.62 \%)$. The next common origin was observed to be from celiac trunk (32.5\%). The variations in origin of inferior phrenic arteries were found more on the right side when compared to the left. We also observed rare vessels of origin like renal arteries, hepatic artery and a case of common trunk origin with other lateral branches of aorta. Association of these variations with multiple renal arteries and gender were found to be statistically insignificant. The degree of variations in origin of inferior phrenic arteries among South Indian population obtained in this study is comparable with most of the studies done in this regard around the world. Taking into account the paucity of information in this regard, we hope this study would aid the clinicians to identify the origin and course of inferior phrenic arteries during the trans catheter arterial chemoembolization procedures for treating hepatic malignancies. It will also help the surgeons during surgical procedures in the upper abdomen.

\section{ACKNOWLEDGEMENT}

We would like to thank Dr. Sheela B, Professor and Head of The Department of Anatomy, Government Medical College,
Thrissur, for her guidance and support. We sincerely thank Dr. Thomas Mathew, former Head of the Department, Department of Forensic Medicine, Government Medical College, Thrissur, for allowing us to conduct this study in his department. We express our sincere gratitude to Dr. Sathi Devi, Associate Professor, Department of Anatomy, Government Medical College, Thrissur, for her valuable advice and support right from the beginning of this study. We would also like to thank all staff of departments of anatomy and forensic medicine of Government Medical College, Thrissur for their help. Above all, we are extremely grateful to those souls who donated their body to the Department of Anatomy. It is on those cadavers; we learned to feel human anatomy and were inspired into this research work.

\section{REFERENCES}

[1] Moore KL, Dalley AF. Clinically oriented anatomy. 4th edn. Baltimore: Lippincott Williams \& Wilkins 1999: p. 339-43.

[2] Standring S. Gray's Anatomy. Chap - 61. The anatomical basis of clinical practice: posterior abdominal wall and retroperitonium. 40 4 th $\mathrm{edn}$. Elsevier/ Churchill Livingstone Ltd., 2008: p. 1072-4.

[3] Takada K, Ito T, Kumada T, et al. Extra-hepatic feeding arteries of hepatocellular carcinoma: an investigation based on intra-arterial CT aortography images using an angio-MDCT system. European Journal of Radiology 2016;85(8):1400-6.

[4] Gokan T, Hashimoto T, Matsui S, et al. Helical CT demonstration of dilated right inferior phrenic arteries as extrahepatic collateral arteries of hepatocellular carcinomas. Journal of Computer Assisted Tomography 2001;25(1):68-73.

[5] Albahhar M, Vo HA, Bowers H, et al. Embolization of non-bronchial systemic artery (inferior phrenic) as a source of massive hemoptysis in a patient with mycobacterial bronchiectasis. In A40. Cystic fibrosis and non-cystic fibrosis bronchiectasis. Am J Res \& Crit Care Med 2017;195:A1491.

[6] Loukas M, Hullett J, Wagner T. Clinical anatomy of the inferior phrenic artery. Clinical Anatomy 2005;18(5):357-65.

[7] Pulakunta T, Potu BK, Gorantla VR, et al. The origin of the inferior phrenic artery: a study in 32 South Indian cadavers with a review of the literature. Journal Vascular Brasileiro 2007;6(3):225-30.

[8] Kahn PC. Selective angiography of the inferior phrenic arteries. Radiology 1967;88(1):1-8.

[9] Piao DX, Ohtsuka A, Murakami T. Typology of abdominal arteries, with special reference to inferior phrenic arteries and their esophageal branches. Acta Medica Okayama 1998;52(4):189-96.

[10] Basile A, Tsetis D, Montineri A, et al. MDCT anatomic assessment of right inferior phrenic artery origin related to potential supply to hepatocellular carcinoma and its embolization. Cardiovascular and Interventional Radiology 2008;31(2):349-58.

[11] Akhilandeswari B, Ranganath P. Variations in the source of origin of inferior phrenic artery: a cadaveric study. Journal of the Anatomical Society of India 2013;62(1):6-9. 


\section{Jemds.com}

[12] Gwon DI, Ko GY, Yoon HK, et al. Inferior phrenic artery: anatomy, variations, pathologic conditions and interventional management. Radiographics 2007;27 (3):687-705.

[13] Yahel J, Arensburg B. The topographic relationships of the unpaired visceral branches of the aorta. Clin Anat 1998;11(5):304-9.

\section{Original Research Article}

[14] Dutta AK. Essentials of human embryology. Chap - 16. $6^{\text {th }}$ edn. Current Books 2013: p. 181-2.

[15] Duprat G, Charnsangavej C, Wallace S, et al. Inferior phrenic artery embolization in the treatment of hepatic neoplasms. Acta Radiologica 1988;29(4):42730 . 